\title{
Recovery of Gold from Pregnant Thiosulfate Solutions by the Resin Adsorption Technique
}

\author{
Zhonglin Dong, Tao Jiang, Bin Xu *, Yongbin Yang and Qian Li * \\ School of Minerals Processing and Bioengineering, Central South University, Changsha 410083, China; \\ dongzhonglincsu@csu.edu.cn (Z.D.); jiangtao@mail.csu.edu.cn (T.J.); ybyangcsu@126.com (Y.Y.) \\ * Correspondence: xubincsu@csu.edu.cn (B.X.); csuliqian@126.com (Q.L.); \\ Tel.: +86-150-849-33770 (B.X.); +86-135-741-99228 (Q.L.)
}

Received: 14 November 2017; Accepted: 6 December 2017; Published: 12 December 2017

\begin{abstract}
This review is devoted to an integrated evaluation of the current use and future development of the resin adsorption technique in gold recovery from pregnant thiosulfate solutions. Comparisons are firstly made with other recovery techniques, including precipitation, activated carbon adsorption, solvent extraction, electrowinning and mesoporous silica adsorption. A detailed discussion about the recent advances of the technique in gold recovery from pregnant thiosulfate solutions is then presented from the aspects of gold adsorption on the resins and gold-loaded resin elution, respectively. On the basis of summarizing the present research, the major limitations of the resin adsorption technique are eventually pointed out and future development will also be prospected.
\end{abstract}

Keywords: gold recovery; pregnant thiosulfate solutions; resin adsorption technique; competitive adsorption; eluent

\section{Introduction}

Cyanide leaching has been used to leach gold from ores for more than a century because of its simple process, high efficiency and low cost. However, there are increasing public worries over the sustained use of cyanide because it is extremely poisonous and can readily cause serious environmental and health problems. In addition, cyanide leaching shows unsatisfactory performance on refractory gold ores such as those containing copper or "preg-robbing" carbon [1]. So, considerable attention has been paid to non-cyanide techniques. Of the alternative techniques, thiosulfate leaching offers the advantages of non-toxicity, low reagent costs, fast leaching rate and good performance in treating certain refractory gold ores, and thus, has been widely accepted by researchers as the most promising non-cyanide technique to replace conventional cyanidation $[2,3]$.

Nevertheless, the successful commercial application of thiosulfate leaching is still rare up to now, except for the development of an ammonia-free thiosulfate leaching process by Barrick Gold Corporation to treat a carbon-bearing sulfide gold ore pretreated with acidic or alkaline pressure oxidation [4,5] whose simplified process flowsheet is presented in Figure 1. Certain factors can account for this, but one of the primary impediments is the difficulty in recovering gold from pregnant thiosulfate solutions [6]. Gold leaching from its ores using thiosulfate solutions has been extensively investigated and is relatively well understood over the past several decades [7-32]. However, limited studies on gold recovery from its leach solutions have been carried out. In recent years, there have been some attempts to recover gold from pregnant thiosulfate solutions by several recovery techniques whose characteristics are summarized and evaluated in Table 1. These studies have indicated that resin adsorption is more suitable compared with other recovery techniques, including precipitation, activated carbon adsorption, solvent extraction, electrowinning and mesoporous silica adsorption. 


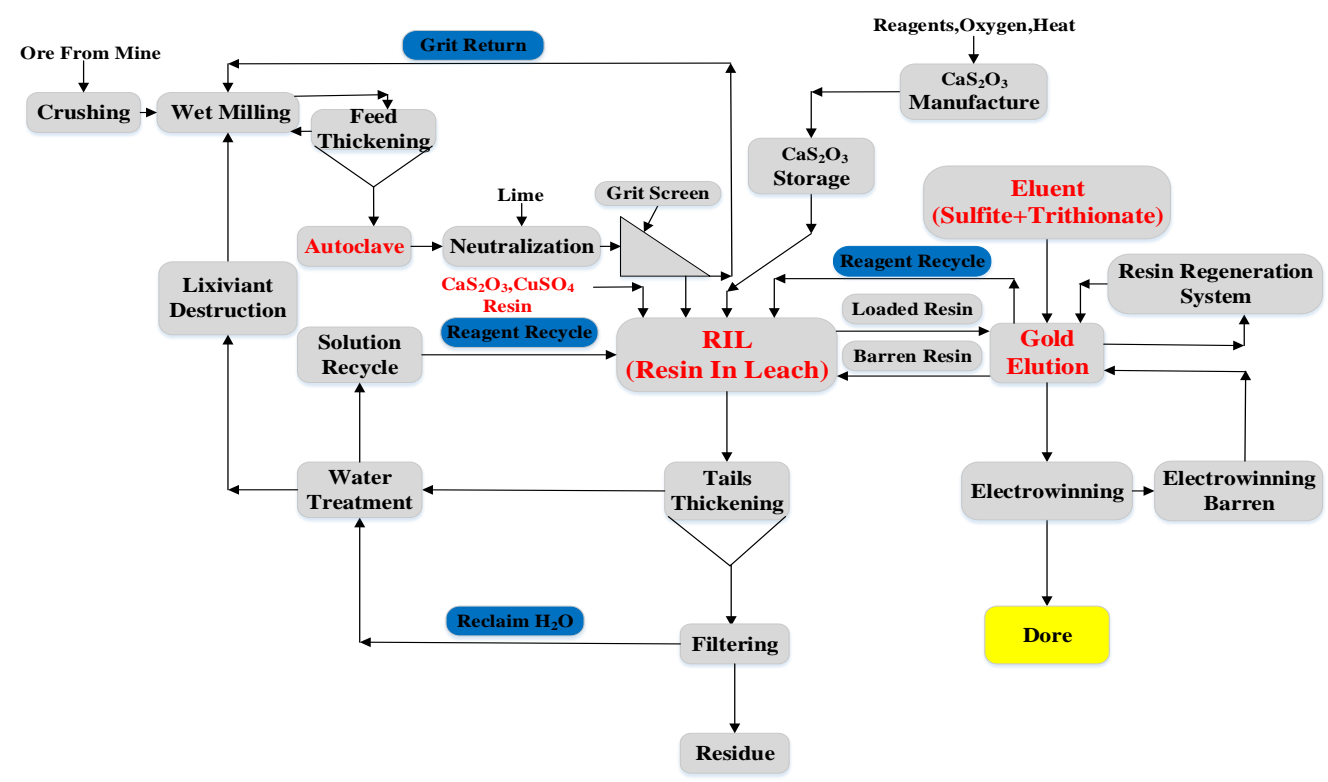

Figure 1. Ammonia-free thiosulfate leaching process by Barrick Gold Corporation to treat a carbon-bearing sulfide gold ore pretreated with acidic or alkaline pressure oxidation $[4,5]$.

Table 1. Evaluation of various gold recovery techniques from pregnant thiosulfate solutions.

\begin{tabular}{|c|c|c|}
\hline Recovery Techinique & Characteristics & References \\
\hline Precipitation & $\begin{array}{l}\text { Technique is simple } \\
\text { High consumption of precipitation agents. } \\
\text { Low-purity gold product } \\
\text { Difficulty in cyclic utilization of pregnant thiosulfate solutions }\end{array}$ & [33-41] \\
\hline $\begin{array}{l}\text { Activated carbon } \\
\text { adsorption }\end{array}$ & $\begin{array}{l}\text { Low requirements on the clarity of solutions } \\
\text { Weak affinity for }\left[\mathrm{Au}\left(\mathrm{S}_{2} \mathrm{O}_{3}\right)_{2}\right]^{3-} \text { anion } \\
\text { Modification is necessary to improve its gold loading capacity }\end{array}$ & [42-54] \\
\hline Solvent extraction & $\begin{array}{l}\text { Pregnant thiosulfate solutions with high gold concentration is needed } \\
\text { High equipment and operating costs due to complete solid-liquid separation of pulp } \\
\text { Dissolution and accumulation of organic extractant is inevitable }\end{array}$ & [55-63] \\
\hline Electrowinning & $\begin{array}{l}\text { Technique is simple } \\
\text { Low current efficiency and high energy consumption due to the undesirable reactions } \\
\text { Difficulty in cyclic utilization of pregnant thiosulfate solutions }\end{array}$ & [64-67] \\
\hline $\begin{array}{l}\text { Mesoporous silica } \\
\text { adsorption }\end{array}$ & $\begin{array}{l}\text { High gold loading capacity } \\
\text { Separation difficulty between pulp and adsorbent dut to its fine particle size } \\
\text { High requirements on the solution } \mathrm{pH} \text { values }\end{array}$ & [68-73] \\
\hline Resin adsorption & $\begin{array}{l}\text { Fast adsorption speed and high gold loading capacity } \\
\text { Low requirements on the clarity of solutions } \\
\text { Simultaneous elution and regeneration at ambient temperature through the elaborate } \\
\text { choice of eluent } \\
\text { Difficulty in gold elution from gold-loaded resins }\end{array}$ & [74-80] \\
\hline
\end{tabular}

Precipitation, also known as the Merrill-Crowe process or cementation, is a common technique for gold recovery from pregnant thiosulfate solutions mainly with metallic powders such as zinc, iron and aluminium [33]. However, additional copper must be added if the solutions are returned to the leaching circuit because copper ions in the solutions are also precipitated out by these metallic powders. Also, these undesirable cations introduce may prevent gold leaching in a thiosulfate leach solution [34]. The use of copper powder is a reasonable choice to avoid the above problems, but the dissolution of copper increases the redox potential of solution and causes the re-dissolution of precipitated gold and enormous oxidation of thiosulfate [35-37]. Furthermore, the dosages of metallic powders needed in precipitation are usually much more than theoretical amounts because the metal surfaces are readily passivated in the solution, therefore resulting in low-purity gold product [38]. In addition, dissolved 
gold in pregnant thiosulfate solutions can also be reduced by the addition of sodium borohydride and soluble sulfides [39-41]. Unfortunately, the extensive co-precipitation of other metals, particularly copper, in solution also occurs, necessitating further purification of the obtained gold product.

Activated carbon adsorption shows good performance in gold recovery from cyanide solutions because of its high efficiency, moderate cost and high purity of product. However, activated carbon has remarkably less affinity for $\left[\mathrm{Au}\left(\mathrm{S}_{2} \mathrm{O}_{3}\right)_{2}\right]^{3-}$ anion than $\left[\mathrm{Au}(\mathrm{CN})_{2}\right]^{-}$anion [42-47], and the potential reasons are the relatively high negative charge of the $\left[\mathrm{Au}\left(\mathrm{S}_{2} \mathrm{O}_{3}\right)_{2}\right]^{3-}$ anion, steric limitations or specific interactions between the ligand group and carbon active sites [48]. It has been proposed that the affinity order of activated carbon for various gold complexes is: $\left[\mathrm{Au}(\mathrm{SCN})_{2}\right]^{-}>\mathrm{Au}\left[\mathrm{SC}\left(\mathrm{NH}_{2}\right)_{2}\right]_{2}{ }^{+}>$ $\left[\mathrm{Au}(\mathrm{CN})_{2}\right]^{-}>\left[\mathrm{Au}\left(\mathrm{S}_{2} \mathrm{O}_{3}\right)_{2}\right]^{3-}[49-51]$. The low affinity of activated carbon for $\left[\mathrm{Au}\left(\mathrm{S}_{2} \mathrm{O}_{3}\right)_{2}\right]^{3-}$ anion makes it difficult to recover gold from pregnant thiosulfate solutions. Two methods can be adopted to improve the recovery technique. One is to add a certain amount of cyanide into the pregnant solutions to produce a more stable gold cyanide complex, followed by adsorption on the activated carbon [52,53]. Another is to modify activated carbon by cyano-cuprous or cupric ferrocyanide [54]. However, the introduction of any cyanide in the two approaches makes the gold recovery process not cyanide-free, which thus cannot be considered as a true alternative to cyanide process.

There have also been some attempts to recover gold from pregnant thiosulfate solutions by solvent extraction technique [55-62]. However, there are several factors limiting its possible commercial application scopes. One is that solvent extraction is suitable for the treatment of clarified solutions containing relatively higher gold concentration than that of resin adsorption. Thus, the complete solid-liquid separation of pulp before extraction is needed, necessitating additional equipment and operating costs. Another problem is that organic extractant can dissolve in the aqueous phase in small amounts causing the losses of extractant [63]. In addition, the accumulation of extractant in the solution is detrimental to its cycle use. Therefore, the technique has not been considered to be economical.

Electrowinning is also an option for gold recovery, and $\left[\mathrm{Au}\left(\mathrm{S}_{2} \mathrm{O}_{3}\right)_{2}\right]^{3-}$ anions in the pregnant solutions will migrate to the cathode, being reduced to metallic gold [64-67]. However, it is also not a feasible choice because undesirable reactions of other anions including copper (I) thiosulfate complexes, sulfur-oxygen anions and other metal thiosulfate complexes in the solutions can occur on the electrode surface. This not only decreases the current efficiency and increases energy consumption, but also reduces the purity of gold product. Again, the cyclic utilization of pregnant thiosulfate solutions has also become significantly hard due to the irreversible degradation of thiosulfate during electrowinning.

Mesoporous silica, an ordered mesoporous material which presents high adsorption capacity and selectivity for gold complexes, has also recently been suggested as an alternative to recover gold from pregnant thiosulfate solutions [68-72]. The maximum loading capacity reached about $600 \mathrm{mg}$ gold per gram amine-bearing mesoporous silica and an average $80 \%$ gold recovery can be obtained. However, the adsorption material is a kind of fine powder whose average particle size is only $1 \mu \mathrm{m}$. This limits its practical application to the treatment of pulp due to the separation difficulty between pulp and adsorbent. In addition, it is generally used in neutral condition $(\mathrm{pH} 7.5)$ for a longer lifecycle which means that it may be not suitable for gold recovery from pregnant thiosulfate solutions whose common $\mathrm{pH}$ range is 9-11 [73].

Compared with the above-mentioned techniques, resin adsorption stands out as the most promising gold recovery technique owing to its fast adsorption speed, high loading capacity, low requirements on the clarity of solutions, simultaneous elution and regeneration at ambient temperature through the elaborate choice of eluent. In addition, ion-exchange resins can be custom-made to selectively extract gold because the functional groups can be designed to have high affinity for objective ions in the solution [74-80]. Therefore, resin adsorption is more suitable for gold recovery from pregnant thiosulfate solutions.

In this review, recent advances of gold recovery by the resin adsorption technique from pregnant thiosulfate solutions will be presented in detail. The advantages of strong-base resins over weak-base resins in gold adsorption and the differences of three kinds of elution principles of gold-loaded resins 
are indicated. Afterwards, a relatively comprehensive summary of the existing problems of the resin adsorption technique will be outlined. In the end, the potential development direction will also be proposed to solve these problems.

\section{Progress of Gold Recovery by the Resin Adsorption Technique}

Ion-exchange resin can be used to recover gold from pregnant thiosulfate solutions through the reversible ion-exchange reactions between the counter ions in the resins and gold (I) thiosulfate complex in the solutions. Gold exists predominantly in the form of $\left[\mathrm{Au}\left(\mathrm{S}_{2} \mathrm{O}_{3}\right)_{2}\right]^{3-}$ anion in the solutions, and thus the resins used in gold recovery are all anion exchange resins, including strong and weak-base resins.

\subsection{The Adsorption of Gold on the Ion-Exchange Resins}

\subsubsection{The Adsorption of Gold on the Weak-Base Resins}

Weak-base resins have primary, secondary or tertiary amine functional groups (or a mixture of them) and their ion-exchange properties are dominated by the solution $\mathrm{pH}$ values. In the free-base form, the resins are unable to adsorb the gold (I) thiosulfate complex and thus they must be protonated usually by adding an acid prior to their use for gold recovery Equation (1) [75]. Generally, the greater the number of the protonated amine groups on the resin at a specific $\mathrm{pH}$ value, the higher the potential for a high gold loading capacity. After protonation, the resin can be used to extract gold from pregnant thiosulfate solutions Equation (1).

$$
\begin{gathered}
\left|-\mathrm{NR}_{2}+\mathrm{HX} \Leftrightarrow\right|-\mathrm{NR}_{2} \mathrm{H}^{+} \mathrm{X}^{-} \\
3 \mid-\mathrm{NR}_{2} \mathrm{H}^{+} \mathrm{X}^{-}+\left[\mathrm{Au}\left(\mathrm{S}_{2} \mathrm{O}_{3}\right)_{2}\right]^{3-} \Leftrightarrow\left(\mid-\mathrm{NR}_{2} \mathrm{H}\right)_{3}{ }^{+}\left[\mathrm{Au}\left(\mathrm{S}_{2} \mathrm{O}_{3}\right)_{2}\right]^{3-}+3 \mathrm{X}^{-}
\end{gathered}
$$

where, the symbol $\mathrm{I}$ - indicates the inert backbone, $\mathrm{R}$ denotes the amine functional group and $\mathrm{X}$ represents the counter ions that can be exchanged such as chloride or sulfate.

For weak-base resins, the specific $\mathrm{pH}$ needed for protonation is defined by $\mathrm{pKa}$, i.e., the $\mathrm{pH}$ value that $50 \%$ of the functional groups are protonated. Typical pKa is in the range of $6-8$, and thus most of the weak-base resins will not be protonated adequately in the range of 9-11, which is the common $\mathrm{pH}$ range of thiosulfate solutions [76]. Also, gold loading on weak-base resins markedly decreases with the increase of $\mathrm{pH}$ from 8 to 11 [77]. So, the gold loading ability of weak-base resins is usually very low when they are used to adsorb gold from pregnant thiosulfate solutions, and this has been demonstrated by certain research [77,78]. In addition, although the gold (I) thiosulfate complex is the only desired anion for adsorption, a considerable number of unwanted anions, including copper (I) thiosulfate complexes, sulfur-oxygen anions and other metal thiosulfate complexes in the solutions, can be adsorbed causing the dramatic decrease of gold loading and thus the significant increase of the resin dosage. Therefore, the use of weak-base resins to recover gold from pregnant thiosulfate solutions is not an efficient and economical choice.

\subsubsection{The Adsorption of Gold on the Strong-Base Resins}

Unlike weak-base resins, strong-base resins contain ammonium functional groups and are not limited by the protonation to adsorb the objective ions from solutions [75]. That is, strong-base resins are applicable to gold recovery over a broad $\mathrm{pH}$ range and their gold loading capacity is essentially independent of the solution $\mathrm{pH}$ values [77]. Therefore, they can be directly used to recover gold from pregnant thiosulfate solutions, as portrayed in Equation (3).

$$
\mid-\mathrm{NR}_{3}{ }^{+} \mathrm{X}^{-}+\left[\mathrm{Au}\left(\mathrm{S}_{2} \mathrm{O}_{3}\right)_{2}\right]^{3-} \Leftrightarrow\left(\mid-\mathrm{NR}_{3}\right)_{3}{ }^{+}\left[\mathrm{Au}\left(\mathrm{S}_{2} \mathrm{O}_{3}\right)_{2}\right]^{3-}+3 \mathrm{X}^{-}
$$


Strong-base resins are generally preferred over weak-base resins in terms of gold loading capacity under the given experimental conditions. The test results for these two kinds of resins indicated that gold loading on various strong-base resins reached up to $10-25 \mathrm{~kg} / \mathrm{t}$, but only less than $2 \mathrm{~kg} / \mathrm{t}$ gold loading capacity was attained for weak-base resins [77]. Since strong-base resins have higher gold loading capacity, the effects of the competitive adsorption of other undesirable anions are generally acceptable. Therefore, strong-base resins are a preferred option for the gold recovery from pregnant thiosulfate solutions.

However, strong-base resins also readily adsorb other undesirable anions and consequently show poor selectivity for gold (I) thiosulfate complexes. Evidently, the presence of these competitive anions will decrease gold loading capacity of the resins remarkably. The effects of copper (I) thiosulfate complexes and tetrathionate on the gold loading on various strong-base resins has been studied by Zhang and Dreisinger [77,79]. The gold loading was closely related to the copper concentration in solution and the maximum gold loading dropped by about $70 \%$ as the copper concentration increased from 100 to $500 \mathrm{ppm}$. Tetrathionate was also significantly detrimental to gold adsorption. With the addition of $0.01 \mathrm{M}$ tetrathionate, gold loading on various resins decreased by nearly $90 \%$. However, the sustained increase of tetrathionate concentration did not make further difference because most of the active sites of the resins were occupied by tetrathionate, i.e., the resins were poisoned.

In addition to tetrathionate and copper (I) thiosulfate complex, other sulfur-oxygen anions and metal thiosulfate complexes, such as $\mathrm{S}_{3} \mathrm{O}_{6}{ }^{2-}, \mathrm{SO}_{3}{ }^{2-},\left[\mathrm{Ag}\left(\mathrm{S}_{2} \mathrm{O}_{3}\right)_{2}\right]^{3-},\left[\mathrm{Pb}\left(\mathrm{S}_{2} \mathrm{O}_{3}\right)_{2}\right]^{2-}$ and $\left[\mathrm{Zn}\left(\mathrm{S}_{2} \mathrm{O}_{3}\right)_{2}\right]^{2-}$, are also present in the real leach solutions. These anions can also be adsorbed on the strong-base resins and thus exert an important influence on gold adsorption. A detailed investigation has been conducted with respect to the effects of common sulfur-oxygen anions and metal thiosulfate complexes on the equilibrium loading of gold on the Amberjet 4200 strong-base resin [80]. It was proposed that the affinity orders of the resin for these two kinds of competitive anions in the solution were $\left[\mathrm{Au}\left(\mathrm{S}_{2} \mathrm{O}_{3}\right)_{2}\right]^{3-}>\mathrm{S}_{3} \mathrm{O}_{6}{ }^{2-}, \mathrm{S}_{4} \mathrm{O}_{6}{ }^{2-}>\mathrm{SO}_{3}{ }^{2-}>\mathrm{S}_{2} \mathrm{O}_{3}{ }^{2-}>\mathrm{SO}_{4}{ }^{2-}$ and $\left[\mathrm{Au}\left(\mathrm{S}_{2} \mathrm{O}_{3}\right)_{2}\right]^{3-}>$ $\left[\mathrm{Pb}\left(\mathrm{S}_{2} \mathrm{O}_{3}\right)_{2}\right]^{2-}>>\left[\mathrm{Ag}\left(\mathrm{S}_{2} \mathrm{O}_{3}\right)_{2}\right]^{3-}>\left[\mathrm{Cu}\left(\mathrm{S}_{2} \mathrm{O}_{3}\right)_{3}\right]^{5-}>>\left[\mathrm{Zn}\left(\mathrm{S}_{2} \mathrm{O}_{3}\right)_{2}\right]^{2-}$, respectively. The results indicate that trithionate, tetrathionate and lead (II) thiosulfate complex may have great impact on the equilibrium loading of gold. In addition, although the affinity of the resin for the $\left[\mathrm{Cu}\left(\mathrm{S}_{2} \mathrm{O}_{3}\right)_{3}\right]^{5-}$ anion is weaker than that for the $\left[\mathrm{Au}\left(\mathrm{S}_{2} \mathrm{O}_{3}\right)_{2}\right]^{3-}$ anion, the concentration of $\left[\mathrm{Cu}\left(\mathrm{S}_{2} \mathrm{O}_{3}\right)_{3}\right]^{5-}$ anion is much higher than that of $\left[\mathrm{Au}\left(\mathrm{S}_{2} \mathrm{O}_{3}\right)_{2}\right]^{3-}$ anion in a typical leach solution. As a result of this, the simultaneous loading of a considerable amount of copper with gold on the resins has become one of the primary factors affecting the gold recovery from pregnant thiosulfate solutions.

In order to solve the competitive adsorption problem of copper with gold on the resins, the replacement of traditional cupric-ammonia catalysis has been proposed [81]. Dowex 21K resin was adopted to recover gold from pregnant thiosulfate solutions with nickel catalysis. Nickel was not adsorbed on the resin in the range of $0.0005-0.05 \mathrm{~mol} / \mathrm{L} \mathrm{Ni}^{2+}$ and $0.05-0.2 \mathrm{~mol} / \mathrm{L} \mathrm{S}_{2} \mathrm{O}_{3}{ }^{2-}$, and the maximum gold loading capacity of the resin achieved $95 \mathrm{~kg} / \mathrm{t}$, which is notably higher than that of common strong-base resins in pregnant thiosulfate solutions with copper catalysis. Also, a comparative study about leaching and recovery of gold using ammoniacal thiosulfate solutions with copper, nickel and cobalt catalysis has been conducted in the authors' laboratory [82]. The thiosulfate consumption of copper catalysis is much higher than that of nickel and cobalt catalysis. The competitive adsorption of nickel or cobalt along with gold did not occur when Tulsion A-21S strong-base resin was used to adsorb gold from their pregnant thiosulfate solutions. Evidently, the absence of competitive adsorption of nickel or cobalt with gold is extremely advantageous to the gold recovery because gold loading on the resin will increase substantially and the problem in separating gold and nickel or cobalt on the resin will also not need to be considered, therefore reducing the gold recovery cost considerably.

\subsection{The Elution of Gold-Loaded Resins}

The selection of eluents is critical because it not only determines the feasibility of cyclic utilization of leach solutions to some degree but also affects the subsequent gold recovery from the eluate solution. 
In addition, elution process of gold-loaded resins is complex due to the loading of a large quantity of copper on the resins, and thus the gold and copper can be considered to be eluted simultaneously or separately. For one-step elution process, additional operations for separating these two metals from the eluate solution were needed in order to obtain final high-purity gold product, but this can easily cause the gold loss. Therefore, the complete separation of gold and copper from the resin is a preferred choice through the elaborate choice of eluents for them. Since the affinity of the common gold extraction resins for gold (I) thiosulfate complex is higher than that for copper (I) thiosulfate complex, copper will also be stripped during gold elution. Thus, pre-elution of copper is desirable to prevent the final gold product from being contaminating by the copper. The copper can be selectively pre-eluted with the solutions of oxygenated ammonia, ammonia-ammonium sulfate, ammonium thiosulfate, etc. and hence this paper mainly concentrates on the elution of gold based on different elution principles.

\subsubsection{The Elution of Gold by Chemical Reaction}

As shown in Figure 2(1)), the resin is loaded with large amounts of $\left[\mathrm{Au}\left(\mathrm{S}_{2} \mathrm{O}_{3}\right)_{2}\right]^{3-}$ anions when adsorption is completed. The chemical reaction principle is that the original $\left[\mathrm{Au}\left(\mathrm{S}_{2} \mathrm{O}_{3}\right)_{2}\right]^{3-}$ anions are transformed to cationic gold complexes through the replacement of thiosulfate ligand [80]. The resins have noticeably reduced affinity for the new-formed cationic complex than gold (I) thiosulfate complex, and thus gold can be readily eluted from the resins. Unfortunately, few eluents can be applied to strip gold on the resins by this principle because the alternative ligand that can replace thiosulfate and complex with gold (I) to form cationic complex is scarce. Acidic thiourea is the only reported for the elution of gold (I) thiosulfate complex by chemical reaction principle [45,83], and the elution reaction of gold is illustrated in Equation (4).

$$
\begin{gathered}
\left(\mid-\mathrm{NR}_{3}\right)_{3}{ }^{+}\left[\mathrm{Au}\left(\mathrm{S}_{2} \mathrm{O}_{3}\right)_{2}\right]^{3-}+2 \mathrm{SC}\left(\mathrm{NH}_{2}\right)_{2}+4 \mathrm{HCl} \\
\rightarrow 3 \mid-\mathrm{NR}_{3}{ }^{+} \mathrm{Cl}^{-}+\mathrm{Au}\left[\mathrm{SC}\left(\mathrm{NH}_{2}\right)_{2}\right]_{2}{ }^{+} \mathrm{Cl}^{-}+2 \mathrm{~S} \downarrow+2 \mathrm{SO}_{2} \uparrow+2 \mathrm{H}_{2} \mathrm{O}
\end{gathered}
$$

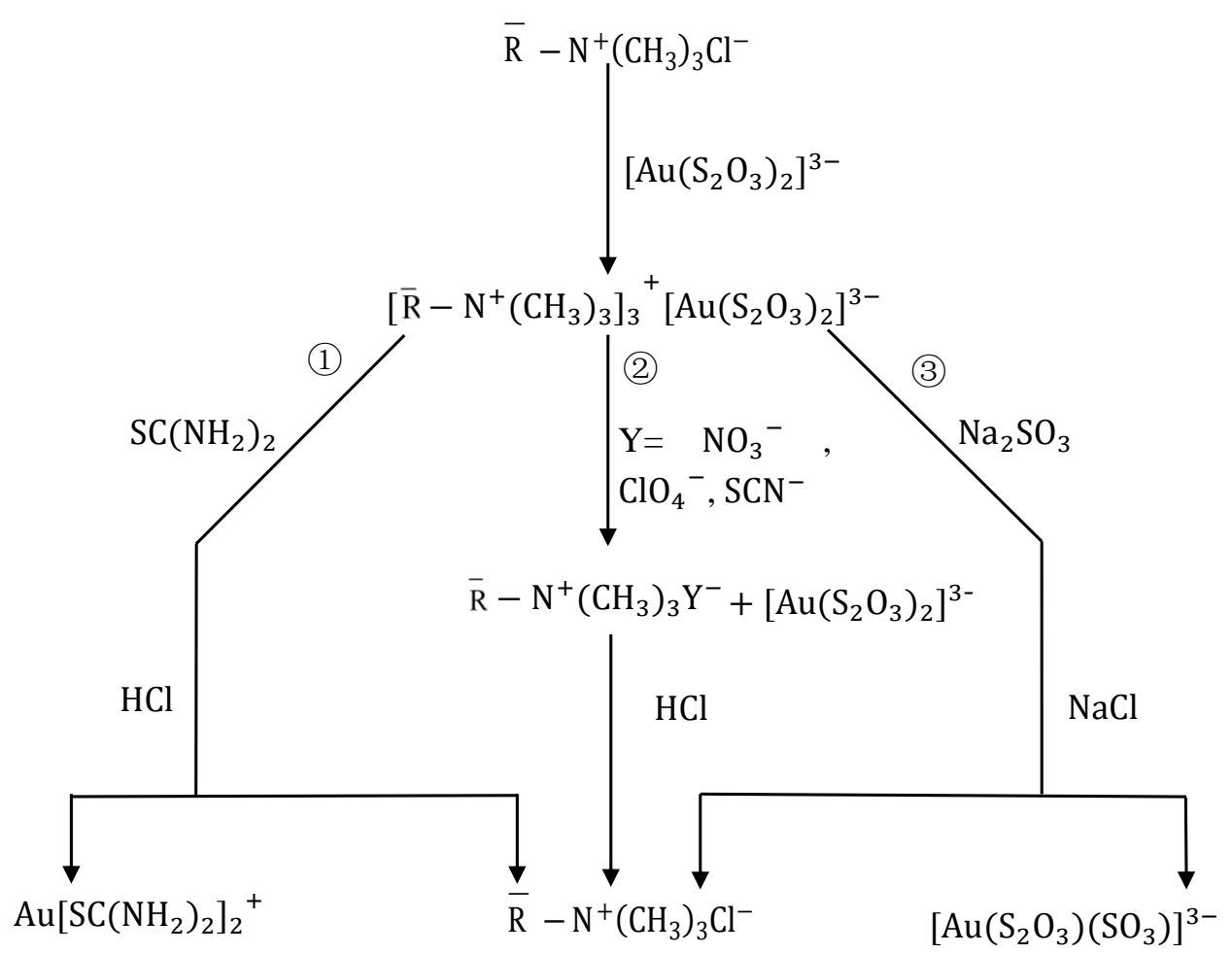

Figure 2. The elution of gold from strong-base resins (1), (2) and (3) represent the elution procedure of $\left[\mathrm{Au}\left(\mathrm{S}_{2} \mathrm{O}_{3}\right)_{2}\right]^{3-}$ anions loaded on the resin through the chemical reaction, displacement and synergistic ion exchange principles, respectively). 
For this gold elution process, regeneration step of the resins is not necessary because the resins only have weak affinity for the chloride, and it can be readily exchanged by $\left[\mathrm{Au}\left(\mathrm{S}_{2} \mathrm{O}_{3}\right)_{2}\right]^{3-}$ anions when the resins are used in the next adsorption circuit. Unfortunately, acidic thiourea is not a viable option because the sulfur-oxygen anions loaded on the resins such as thiosulfate and polythionates are not stable under acidic condition, and sulfur precipitation driving from the breakdown of them can poison the resin. Furthermore, osmotic shock produced by repeated elution in acidic media and adsorption in alkaline media can destroy the resin structure and thus increase recovery cost.

\subsubsection{The Elution of Gold by Displacement}

As indicated in Figure 2(2)), the displacement principle uses an anion with high affinity for the resin to exchange adsorbed $\left[\mathrm{Au}\left(\mathrm{S}_{2} \mathrm{O}_{3}\right)_{2}\right]^{3-}$ anions [80], which is also the most common method to be used in the gold elution. From the perspective of adsorption, the method is essentially achieved by altering the equilibrium of Equation (3) to the left through the increase of the concentration of $\mathrm{X}^{-}$anion. On the basis of this principle, some eluents including thiocyanate, tetrathionate, nitrate and perchlorate have been founded to strip the gold effectively. However, gold elution by this principle usually requires high concentration of eluent because of the strong affinity of the resin for $\left[\mathrm{Au}\left(\mathrm{S}_{2} \mathrm{O}_{3}\right)_{2}\right]^{3-}$ anion, therefore resulting in relatively high reagent cost. Furthermore, it is necessary to adopt an additional regeneration step to change the resin into its original form after gold elution. Otherwise, gold loading capacity of the resin will decrease dramatically due to the sustained accumulation of eluent anions on the resin.

Thiocyanate has been considered to be capable of effectively eluting loaded gold cyanide complex from anion exchange resins because of its strong affinity for the resin [84]. It was also used to elute gold (I) thiosulfate complex from the resin by the same authors, as described in Equation (5). After elution, the gold in the eluate solution was then recovered by conventional electrowinning [85]. However, thiocyanate is not an economical and environmental eluent, and the electrodes can be corroded during the subsequent gold electrowinning from the thiocyanate eluates [84]. After gold elution, sulfuric or hydrochloric acids can be used to regenerate the resin, but the thiocyanate ion degrades readily to elemental sulfur under strongly acidic condition. This is regarded to be undesirable from resin recycling point of view because sulfur precipitation will accumulate in the resin matrix and poison the resin by blocking resin pore. An alternative is to use ferric sulfate to remove the loaded thiocyanate and regenerate the resin to the sulfate form. Meanwhile, the eluted Fe (III) thiocyanate can be recovered by the addition of hydroxide to form Fe (III) hydroxide precipitate and the generated thiocyanate ions can be returned to elution cycle, as presented in Equations (6) and (7). However, this resin regeneration process may lead to resin breakage from osmotic shock driving from the change in $\mathrm{pH}$ from elution to regeneration.

$$
\begin{gathered}
\left(\mid-\mathrm{NR}_{3}\right)_{3}{ }^{+}\left[\mathrm{Au}\left(\mathrm{S}_{2} \mathrm{O}_{3}\right)_{2}\right]^{3-}+3 \mathrm{SCN}^{-} \Leftrightarrow 3 \mid-\mathrm{NR}_{3}{ }^{+} \mathrm{SCN}^{-}+\left[\mathrm{Au}\left(\mathrm{S}_{2} \mathrm{O}_{3}\right)_{2}\right]^{3-} \\
4 \mid-\mathrm{NR}_{3}{ }^{+} \mathrm{SCN}^{-}+\mathrm{Fe}_{2}\left(\mathrm{SO}_{4}\right)_{3} \rightarrow 2\left(\mid-\mathrm{NR}_{3}\right)_{2}{ }^{+} \mathrm{SO}_{4}{ }^{2-}+2 \mathrm{Fe}(\mathrm{SCN})_{2}{ }^{+}+\mathrm{SO}_{4}{ }^{2-} \\
\mathrm{Fe}(\mathrm{SCN})_{2}{ }^{+}+3 \mathrm{OH}^{-} \rightarrow \mathrm{Fe}(\mathrm{OH})_{3} \downarrow+2 \mathrm{SCN}^{-}
\end{gathered}
$$

As a common anion in the pregnant thiosulfate solutions, $\mathrm{S}_{4} \mathrm{O}_{6}{ }^{2-}$ anion can strongly compete with $\left[\mathrm{Au}\left(\mathrm{S}_{2} \mathrm{O}_{3}\right)_{2}\right]^{3-}$ anion for the active sites of the resin, as indicated in Section 2.1.2. As a result of this, it has also been used to effectively elute gold and the stripped resin was regenerated with sulfide ions to convert tetrathionate to thiosulfate [86]. The reactions of gold (I) thiosulfate elution and resin regeneration can be portrayed in Equations (8) and (9).

$$
\begin{gathered}
2\left(\mid-\mathrm{NR}_{3}\right)_{3}{ }^{+}\left[\mathrm{Au}\left(\mathrm{S}_{2} \mathrm{O}_{3}\right)_{2}\right]^{3-}+3 \mathrm{~S}_{4} \mathrm{O}_{6}{ }^{2-} \Leftrightarrow 3\left(\mid-\mathrm{NR}_{3}\right)_{2}{ }^{+} \mathrm{S}_{4} \mathrm{O}_{6}{ }^{2-}+2\left[\mathrm{Au}\left(\mathrm{S}_{2} \mathrm{O}_{3}\right)_{2}\right]^{3-} \\
\left(\mid-\mathrm{NR}_{3}\right)_{2}{ }^{+} \mathrm{S}_{4} \mathrm{O}_{6}{ }^{2-}+2 \mathrm{~S}^{2-} \Leftrightarrow\left(\mid-\mathrm{NR}_{3}\right)_{2}{ }^{+} \mathrm{S}^{2-}+2 \mathrm{~S}_{2} \mathrm{O}_{3}{ }^{2-}+\mathrm{S} \downarrow
\end{gathered}
$$


However, this elution process is also not economical because tetrathionate is highly unstable and will decompose easily, with the result that large amount of eluent solution will be needed. Therefore, the eluent must be freshly made each time the elution of the resin is carried out [80]. The formation of sulfur precipitation is also inevitable during the resin regeneration with sulfide ions, as shown in Equation 9. Furthermore, sulfide precipitates of gold, copper or other metals may form when the resins with sulfide counter ions are return to the gold adsorption stage, which is highly unbeneficial to both the gold recovery and cycle use of the resin.

Apart from thiocyanate and tetrathionate, nitrate could also be adopted to elute gold (Equation 10) and electrowinning was utilized to recover gold from the eluate solution [87]. However, compared with thiocyanate and tetrathionate, much more concentrated nitrate solutions are needed to achieve almost complete gold elution. The potential reason is that the affinity of the resins for nitrate is substantially lower than that of thiocyanate and tetrathionate. It has also been observed that the eluate solution containing gold (I) thiosulfate complex was not stable and black gold precipitate occurred during electrowinning. The potential reason is that gold (I) thiosulfate complex will dissociate due to the lack of the free thiosulfate in the eluate solution, which is further accelerated due to the oxidation decomposition of free thiosulfate. Finally, the gold (I) reacts with the sulfide ions in the solution resulting in the formation of black gold sulfide precipitate.

$$
\left(\mid-\mathrm{NR}_{3}\right)_{3}{ }^{+}\left[\mathrm{Au}\left(\mathrm{S}_{2} \mathrm{O}_{3}\right)_{2}\right]^{3-}+3 \mathrm{NO}_{3}{ }^{-} \Leftrightarrow 3 \mid-\mathrm{NR}_{3}{ }^{+} \mathrm{NO}_{3}{ }^{-}+\left[\mathrm{Au}\left(\mathrm{S}_{2} \mathrm{O}_{3}\right)_{2}\right]^{3-}
$$

In a recent study on the gold elution from the same resin with different gold loading capacities, perchlorate has been found to be an effective eluent (Equation 11) [81]. For $2.0 \mathrm{~g}$ resin with $5 \mathrm{~kg} / \mathrm{t}$ gold loading capacity, nearly $100 \%$ gold can be successfully eluted by $2.5 \mathrm{~mol} / \mathrm{L}$ perchlorate and an eluate with average gold concentration of $300 \mathrm{mg} / \mathrm{L}$ was produced. Moreover, the feasibility of this elution process has been demonstrated by a detailed comparison with the conventional Zadra process that is utilized to elute the loaded $\left[\mathrm{Au}(\mathrm{CN})_{2}\right]^{-}$anions from the activated carbon (Table 2) [88]. It is clear that the perchlorate elution process is superior to the Zadra process with respect to elution time, temperature, gold concentration in the eluate solution, gold recovery, etc. In addition, successful gold recovery by electrowinning from the eluate can be realized because perchlorate is a common electrolyte in the electrochemistry study. Unfortunately, both high concentration of perchlorate solution and resin regeneration are also required.

$$
\left(\mid-\mathrm{NR}_{3}\right)_{3}{ }^{+}\left[\mathrm{Au}\left(\mathrm{S}_{2} \mathrm{O}_{3}\right)_{2}\right]^{3-}+3 \mathrm{ClO}_{4}{ }^{-} \Leftrightarrow 3 \mid-\mathrm{NR}_{3}{ }^{+} \mathrm{ClO}_{4}{ }^{-}+\left[\mathrm{Au}\left(\mathrm{S}_{2} \mathrm{O}_{3}\right)_{2}\right]^{3-}
$$

Table 2. Comparison of $\left[\mathrm{Au}\left(\mathrm{S}_{2} \mathrm{O}_{3}\right)_{2}\right]^{3-}$ anion elution from the resin by the perchlorate process and

\begin{tabular}{|c|c|c|c|c|}
\hline \multirow{2}{*}{$\frac{\text { Parameters }}{\text { Gold loading capacity of resin/carbon } /(\mathrm{kg} / \mathrm{t})}$} & \multicolumn{2}{|c|}{ Perchlorate Process } & \multicolumn{2}{|c|}{ Zadra Process } \\
\hline & 5 & 10 & 20 & $4-5$ \\
\hline Elution time $/ \mathrm{h}$ & 4 & 4 & 4 & $30-48$ \\
\hline Temperature/K & Ambient & Ambient & Ambient & $363-373$ \\
\hline Pressure/kPa & Atmosphere & Atmosphere & Atmosphere & $400-500$ \\
\hline Flow rate/(bed volume number /h) & 3 & 6 & 12 & $1-2$ \\
\hline Maximum gold concentration/(mg/L) & 1250 & 1400 & 1700 & 1000 \\
\hline Average gold concentration/(mg/L) & 333 & 400 & 400 & $150-400$ \\
\hline Gold recovery & $>99.5 \%$ & $>99.5 \%$ & $>99.5 \%$ & $96-98 \%$ \\
\hline Gold loading capacity of stripped resin/carbon $/(\mathrm{kg} / \mathrm{t})$ & $<0.05$ & $<0.05$ & $<0.05$ & 0.15 \\
\hline
\end{tabular}
$\left[\mathrm{Au}(\mathrm{CN})_{2}\right]^{-}$anion elution from activated carbon by the Zadra process [81].

Note: Eluent of perchlorate elution process: $2.5 \mathrm{~mol} / \mathrm{L} \mathrm{NaClO}_{4}$, eluent of Zadra process: $10 \mathrm{~g} / \mathrm{L} \mathrm{NaOH}+2 \mathrm{~g} / \mathrm{L} \mathrm{NaCN}$.

\subsubsection{The Elution of Gold by Synergistic Ion Exchange}

As presented in Figure 2(3)), the third elution principle is based on the concept of "synergistic ion exchange". In this principle, the eluent is a mixture of a weak eluent and sulfite. It is hard for the weak eluent to effectively elute gold loaded on the resins even when high concentration of it is used due to 
the weak affinity of the resin for the eluent anion. However, with the addition of a small amount of sulfite, $\left[\mathrm{Au}\left(\mathrm{S}_{2} \mathrm{O}_{3}\right)_{2}\right]^{3-}$ complex will be converted to $\left[\mathrm{Au}\left(\mathrm{S}_{2} \mathrm{O}_{3}\right)\left(\mathrm{SO}_{3}\right)\right]^{3-}$ complex [89]. The resin has very weak affinity for the new-formed mixed ligand gold (I) thiosulfate-sulfite complex, and thus it can be readily eluted by the weak eluent with relatively low concentration, which is favorable to the decrease of elution costs. Furthermore, resin regeneration is not needed because the weak eluent anion will be readily exchanged by $\left[\mathrm{Au}\left(\mathrm{S}_{2} \mathrm{O}_{3}\right)_{2}\right]^{3-}$ anions when the resin is returned to adsorption circuit, therefore simplifying the whole gold recovery process greatly.

Based on the elution principle, a study about the elution of the gold-loaded resins was conducted [90]. After copper elution, the resin was then stripped to recover gold with a mixed eluent consisting of $2 \mathrm{M}$ sodium chloride and $0.1 \mathrm{M}$ sodium sulfite. Subsequently, electrowinning was utilized to recover gold from the eluate solution. Gold could hardly be eluted using single $2 \mathrm{M}$ sodium chloride solutions, which was also demonstrated by the research of Mohansingh [47]. With the addition of $0.1 \mathrm{M}$ sodium sulfite, however, a complete gold elution could be achieved within $12 \mathrm{BV}$ (bed volume, i.e., the volume of the reactor that is occupied by ion exchange resin) under the eluent flowrate of $5 \mathrm{BV} / \mathrm{h}$. When the eluent flowrate was decreased to $2 \mathrm{BV} / \mathrm{h}$, elution was complete only within $8 \mathrm{BV}$. Therefore, the sulfite significantly facilitates the elution efficiency of sodium chloride, and the probable elution reaction is shown in Equation 12. Another important advantage of the sulfite is that it can reduce the formation of gold sulfide pricipitate during electrowinning and thus significantly improve gold recovery from the eluate solution. Moreover, the addition of sulfite to the eluent can convert higher polythionates including tetrathionate, pentathionate and hexathionate to thiosulfate and trithionate (Equations 13-15). However, it should also be noted that trithionate, the decomposition product of these higher polythionates, can still accumulate on the resin and eventually has a negative effect on gold loading in the adsorption stage, as indicated in Section 2.1.2. In addition, poisonous chlorine may produce during electrowinning due to the presence of high concentration of chloride and thus worsen working conditions.

$$
\begin{gathered}
\left(\mid-\mathrm{NR}_{3}\right)_{3}{ }^{+}\left[\mathrm{Au}\left(\mathrm{S}_{2} \mathrm{O}_{3}\right)_{2}\right]^{3-}+\mathrm{SO}_{3}{ }^{2-}+3 \mathrm{Cl}^{-} \Leftrightarrow 3 \mid-\mathrm{NR}_{3}{ }^{+} \mathrm{Cl}^{-}+\left[\mathrm{Au}\left(\mathrm{S}_{2} \mathrm{O}_{3}\right)\left(\mathrm{SO}_{3}\right)\right]^{3-}+ \\
\mathrm{S}_{2} \mathrm{O}_{3}{ }^{2-} \\
\mathrm{S}_{4} \mathrm{O}_{6}{ }^{2-}+\mathrm{SO}_{3}{ }^{2-} \Leftrightarrow \mathrm{S}_{2} \mathrm{O}_{3}{ }^{2-}+\mathrm{S}_{3} \mathrm{O}_{6}{ }^{2-} \\
\mathrm{S}_{5} \mathrm{O}_{6}{ }^{2-}+2 \mathrm{SO}_{3}{ }^{2-} \Leftrightarrow 2 \mathrm{~S}_{2} \mathrm{O}_{3}{ }^{2-}+\mathrm{S}_{3} \mathrm{O}_{6}{ }^{2-} \\
\mathrm{S}_{6} \mathrm{O}_{6}{ }^{2-}+3 \mathrm{SO}_{3}{ }^{2-} \Leftrightarrow 3 \mathrm{~S}_{2} \mathrm{O}_{3}{ }^{2-}+\mathrm{S}_{3} \mathrm{O}_{6}{ }^{2-}
\end{gathered}
$$

\section{The Main Limitations of the Resin Adsorption Technique}

The resin adsorption technique is the most suitable choice to recover gold from pregnant thiosulfate solutions compared with other recovery techniques, as mentioned in Introduction. However, there are still certain problems to be addressed to further develop the technique.

\subsection{The Competitive Adsorption of Undesirable Anions}

Thiosulfate is generally considered as being metastable, which means that some oxidative decomposition reactions can occur in a typical leaching environment, as described in Equations (16) and (17). In addition, in the thiosulfate leaching system, copper and ammonia are added to accelerate gold dissolution through the formation of copper (II) ammine complexes. However, a problem associated with the use of cupric ammine is that it accelerates the oxidation of thiosulfate to produce tetrathionate, which is also unstable and can be easily degraded into trithionate and thiosulfate [91-95], as presented in Equations (18) and (19).

$$
3 \mathrm{~S}_{2} \mathrm{O}_{3}{ }^{2-}+2 \mathrm{O}_{2}+\mathrm{H}_{2} \mathrm{O} \rightarrow 2 \mathrm{~S}_{3} \mathrm{O}_{6}{ }^{2-}+2 \mathrm{OH}^{-}
$$




$$
\begin{gathered}
4 \mathrm{~S}_{2} \mathrm{O}_{3}{ }^{2-}+\mathrm{O}_{2}+2 \mathrm{H}_{2} \mathrm{O} \rightarrow 2 \mathrm{~S}_{4} \mathrm{O}_{6}{ }^{2-}+4 \mathrm{OH}^{-} \\
2\left[\mathrm{Cu}\left(\mathrm{NH}_{3}\right)_{4}\right]^{2+}+8 \mathrm{~S}_{2} \mathrm{O}_{3}{ }^{2-} \rightarrow 2\left[\mathrm{Cu}\left(\mathrm{S}_{2} \mathrm{O}_{3}\right)_{3}\right]^{5-}+8 \mathrm{NH}_{3}+\mathrm{S}_{4} \mathrm{O}_{6}{ }^{2-} \\
4 \mathrm{~S}_{4} \mathrm{O}_{6}{ }^{2-}+6 \mathrm{OH}^{-} \rightarrow 5 \mathrm{~S}_{2} \mathrm{O}_{3}{ }^{2-}+2 \mathrm{~S}_{3} \mathrm{O}_{6}{ }^{2-}+3 \mathrm{H}_{2} \mathrm{O}
\end{gathered}
$$

The degradation products of thiosulfate, particularly polythionates including trithionate and tetrathionate, will intensely compete with gold (I) thiosulfate complex for active sites in the resins, and low concentration of them in the leach solution will decrease gold loading capacity of the resins tremendously. Therefore, it is very necessary to minimize the generation of them in the leaching stage to ensure an efficient gold recovery from the pregnant thiosulfate solutions by the resin adsorption technique.

It should be noticed that the cupric ammine itself is also reduced to $\left[\mathrm{Cu}\left(\mathrm{S}_{2} \mathrm{O}_{3}\right)_{3}\right]^{5-}$ when it accelerate the oxidation of thiosulfate, as shown in Equation 18. Copper (I) thiosulfate complex is more stable than its ammine complex thermodynamically [81], and thus copper (I) exists primarily as thiosulfate complex in the pregnant thiosulfate solutions. Substantial amounts of $\left[\mathrm{Cu}\left(\mathrm{S}_{2} \mathrm{O}_{3}\right)_{3}\right]^{5-}$ can readily load on the resins with $\left[\mathrm{Au}\left(\mathrm{S}_{2} \mathrm{O}_{3}\right)_{2}\right]^{3-}$ due to the same ligand of these two complex anions. For this reason, it is very difficult to selectively adsorb gold (I) thiosulfate complex from pregnant thiosulfate solutions. The co-adsorption of copper (I) also makes it necessary to adopt a complex and costly two-stage elution process to separate the copper and gold loaded on the resins.

Apart from polythionates and copper (I) thiosulfate complex, other metal thiosulfate complexes, such as $\left[\mathrm{Ag}\left(\mathrm{S}_{2} \mathrm{O}_{3}\right)_{2}\right]^{3-},\left[\mathrm{Pb}\left(\mathrm{S}_{2} \mathrm{O}_{3}\right)_{2}\right]^{2-}$ and $\left[\mathrm{Zn}\left(\mathrm{S}_{2} \mathrm{O}_{3}\right)_{2}\right]^{2-}$, may also exist in the real leach solutions [80]. Their effects on the gold adsorption on the resins can also usually not be neglected because they are able to load on the resins. The competitive adsorption of them with gold (I) thiosulfate complex not only decreases the gold loading capacity of the resins but also complicates subsequent elution process.

\subsection{The Lack of Suitable Gold Extraction Resin and Eluent}

Most of the available resins used in current research on gold recovery from pregnant thiosulfate solutions are those which show good performance for gold recovery from pregnant cyanide solutions (Table 3) [96-99]. However, these resins are generally not highly selective for $\left[\mathrm{Au}\left(\mathrm{S}_{2} \mathrm{O}_{3}\right)_{2}\right]^{3-}$ anion because they were designed to adsorb singly charged $\left[\mathrm{Au}(\mathrm{CN})_{2}\right]^{-}$anion. Furthermore, the presence of a series of competitive anions, including copper (I) thiosulfate complexes, sulfur-oxygen anions and other metal thiosulfate complexes in the solutions also places greater demands on the selectivity of the resin. Nevertheless, the selectivity of the resin is a complex subject, which is mainly determined by the properties of the resin itself and the anion. For the resin, the functional group, hydrophobicity of the polymeric matrix, porosity and ion identity (number of ionic groups per unit volume) of the resin are all important factors influencing its selectivity for the anion [100,101]. Also, previous studies on the adsorption of metal cyanide anions on both strong- and weak-base resins indicated that the properties of the anion, including polarisability, charge density (the ratio of the charge to the number of atoms), the degree of hydration and the shape or size, give an indication of what type of resin will be suitable for gold recovery [101-104]. Taking the above properties of the anion into consideration in a thiosulfate solution, O'Malley [80] proposed the likely selectivity orders of the resin for sulfur-oxygen anions and metal thiosulfate complexes (Tables 4 and 5), which also were supported by certain research results [105-107]. However, research on the selectivity of the resin for $\left[\mathrm{Au}\left(\mathrm{S}_{2} \mathrm{O}_{3}\right)_{2}\right]^{3-}$ anion has been rare up to now and there is still much work to be done to design a resin highly selective for gold (I) thiosulfate complex. 
Table 3. The resins used for gold recovery from pregnant thiosulfate solutions.

\begin{tabular}{|c|c|c|c|c|c|c|c|c|c|c|}
\hline \multicolumn{9}{|c|}{ Adsorption Conditions } & \multirow{2}{*}{$\mathrm{Au} / \%^{2}$} & \multirow{2}{*}{ Reference } \\
\hline Resin & Type & {$[\mathrm{Au}]^{1}$} & {$[\mathrm{Cu}]^{1}$} & {$\left[\mathrm{~S}_{2} \mathrm{O}_{3}{ }^{2-}\right]$} & {$\left[\mathrm{NH}_{3}\right]$} & $\mathrm{pH}$ & $\mathrm{T} /{ }^{\circ} \mathrm{C}$ & Time/h & & \\
\hline AV-17-10P & $\mathrm{R}_{4} \mathrm{~N}^{+}$ & $9.5-17.9$ & - & 0.5 & 0.5 & $10.8-11.0$ & - & 5 & 94.2 & [45] \\
\hline Purolite A500C & $\mathrm{R}_{4} \mathrm{~N}^{+}$ & 1.8 & 22 & 0.05 & 0.1 & 8 & 60 & 6 & 99.45 & [96] \\
\hline Amberlite IRA 400 & $\mathrm{R}_{4} \mathrm{~N}^{+}$ & 9.27 & 125 & 1.0 & 0.1 & 9 & 20 & 10 & 94.7 & [47] \\
\hline Amberjet 4200 & $\mathrm{R}_{4} \mathrm{~N}^{+}$ & 10 & 10 & 0.5 & 0.2 & 9.5 & - & - & 99 & [80] \\
\hline Amberlite IRA 410 & $\mathrm{R}_{4} \mathrm{~N}^{+}$ & 8 & 100 & 0.1 & 0.1 & 11 & 25 & 2 & $>90$ & [97] \\
\hline Purolite A530 & $\mathrm{R}_{4} \mathrm{~N}^{+}$ & 39.4 & - & 0.5 & - & 10 & - & - & 94 & [78] \\
\hline Dowex G51 & $\mathrm{R}_{4} \mathrm{~N}^{+}$ & 10 & 500 & 0.1 & - & 11.7 & 23 & - & 98 & [98] \\
\hline Amberlite IRA-93 & WB & 10 & - & 0.1 & - & 8 & 23 & 2 & 94.3 & [98] \\
\hline Aurix 100 & Guan & $1-8$ & - & $0.00674-0.04$ & $0.30-0.81$ & 9-10.5 & $25-40$ & $0-3$ & 99 & [99] \\
\hline
\end{tabular}

Note: All the results were obtained under batch experiment condition. $\mathrm{R}_{4} \mathrm{~N}^{+}$: quaternary ammonium (strong base); WB: weak base; Guan: guanidyl. "_" denotes "absence" of the items or "the literature did not mention", "T" represents temperature. ${ }^{1}$ Reported in ppm. ${ }^{2}$ Gold recovery $(\%) .{ }^{3}$ Nickel concentration.

Table 4. Predicted selectivity of the resin for sulfur-oxygen anions presented in declining order.

\begin{tabular}{cccccc}
\hline Name & Formula & Formula Weight & Polarizability & Charge Density & Hydration \\
\hline Pentathionate & $\mathrm{S}_{5} \mathrm{O}_{6}{ }^{2-}$ & 256.5 & High & 0.18 & High \\
Tetrathionate & $\mathrm{S}_{4} \mathrm{O}_{6}{ }^{2-}$ & 224.3 & High & 0.2 & High \\
Trithionate & $\mathrm{S}_{3} \mathrm{O}_{6}{ }^{2-}$ & 192.2 & High & 0.22 & High \\
Dithionate & $\mathrm{S}_{2} \mathrm{O}_{6}{ }^{2-}$ & 160.1 & Medium & 0.25 & High \\
Dithionite & $\mathrm{S}_{2} \mathrm{O}_{4}{ }^{2-}$ & 128.2 & Medium & 0.33 & Medium \\
Thiosulfate & $\mathrm{S}_{2} \mathrm{O}_{3}{ }^{2-}$ & 112.2 & Medium & 0.4 & Medium \\
Sulfate & $\mathrm{SO}_{4}{ }^{2-}$ & 96.1 & Low & 0.4 & Medium \\
Sulfite & $\mathrm{SO}_{3}{ }^{2-}$ & 80.1 & Low & 0.5 & Medium \\
\hline
\end{tabular}

Table 5. Predicted selectivity of the resin for metal thiosulfate complexes presented in declining order.

\begin{tabular}{cccccc}
\hline Name & Formula & Formula Weight & Polarizability & Charge Density & Hydration \\
\hline Silver (I) thiosulfate & {$\left[\mathrm{Ag}\left(\mathrm{S}_{2} \mathrm{O}_{3}\right)_{3}\right]^{5-}$} & 444.3 & High & 0.13 & NK \\
Copper (I) thiosulfate & {$\left[\mathrm{Cu}\left(\mathrm{S}_{2} \mathrm{O}_{3}\right)_{3}\right]^{--}$} & 400.1 & High & 0.13 & NK \\
Lead (II) thiosulfate & {$\left[\mathrm{Pb}\left(\mathrm{S}_{2} \mathrm{O}_{3}\right)_{3}\right]^{4-}$} & 543.7 & High & 0.25 & NK \\
Gold (I) thiosulfate & {$\left[\mathrm{Au}\left(\mathrm{S}_{2} \mathrm{O}_{3}\right)_{2}\right]^{3-}$} & 421.3 & High & 0.27 & Low \\
Lead (II) thiosulfate & {$\left[\mathrm{Pb}\left(\mathrm{S}_{2} \mathrm{O}_{3}\right)_{2}\right]^{2-}$} & 431.5 & High & 0.18 & NK \\
Silver (I) thiosulfate & {$\left[\mathrm{Ag}\left(\mathrm{S}_{2} \mathrm{O}_{3}\right)_{2}\right]^{3-}$} & 332.2 & High & 0.27 & Low \\
Copper (I) thiosulfate & {$\left[\mathrm{Cu}\left(\mathrm{S}_{2} \mathrm{O}_{3}\right)_{2}\right]^{3-}$} & 287.8 & High & 0.27 & NK \\
Zinc (II) thiosulfate & {$\left[\mathrm{Zn}\left(\mathrm{S}_{2} \mathrm{O}_{3}\right)_{2}\right]^{2-}$} & 289.6 & High & 0.18 & High \\
\hline
\end{tabular}

Note: “NK" denotes "not known".

Gold can be effectively adsorbed by strong-base resins from pregnant thiosulfate solutions. The gold-loaded resins are pre-eluted to remove copper, and the pre-eluate containing high concentration of copper will be returned to the leaching circuit. However, to seek for an applicable eluent of gold has been proven problematic mainly owning to the strong affinity of the resins for $\left[\mathrm{Au}\left(\mathrm{S}_{2} \mathrm{O}_{3}\right)_{2}\right]^{3-}$ anion. Most of the eluents proposed previously, such as the single component solutions of thiocyanate, tetrathionate, nitrate and perchlorate or the two component solutions such as thiourea + sulfuric/hydrochloric acids and sodium sulfite + sodium chloride, are all not ideal due to either high reagent cost or environmental pollution, and the characteristics of them are summarized and evaluated in Table 6. Therefore, the development of an appropriate eluent to elute the gold from the resins will be one of the feasible measures to further develop the resin adsorption technique. 
Table 6. Evaluation of various elution processes for $\left[\mathrm{Au}\left(\mathrm{S}_{2} \mathrm{O}_{3}\right)_{2}\right]^{3-}$ anion.

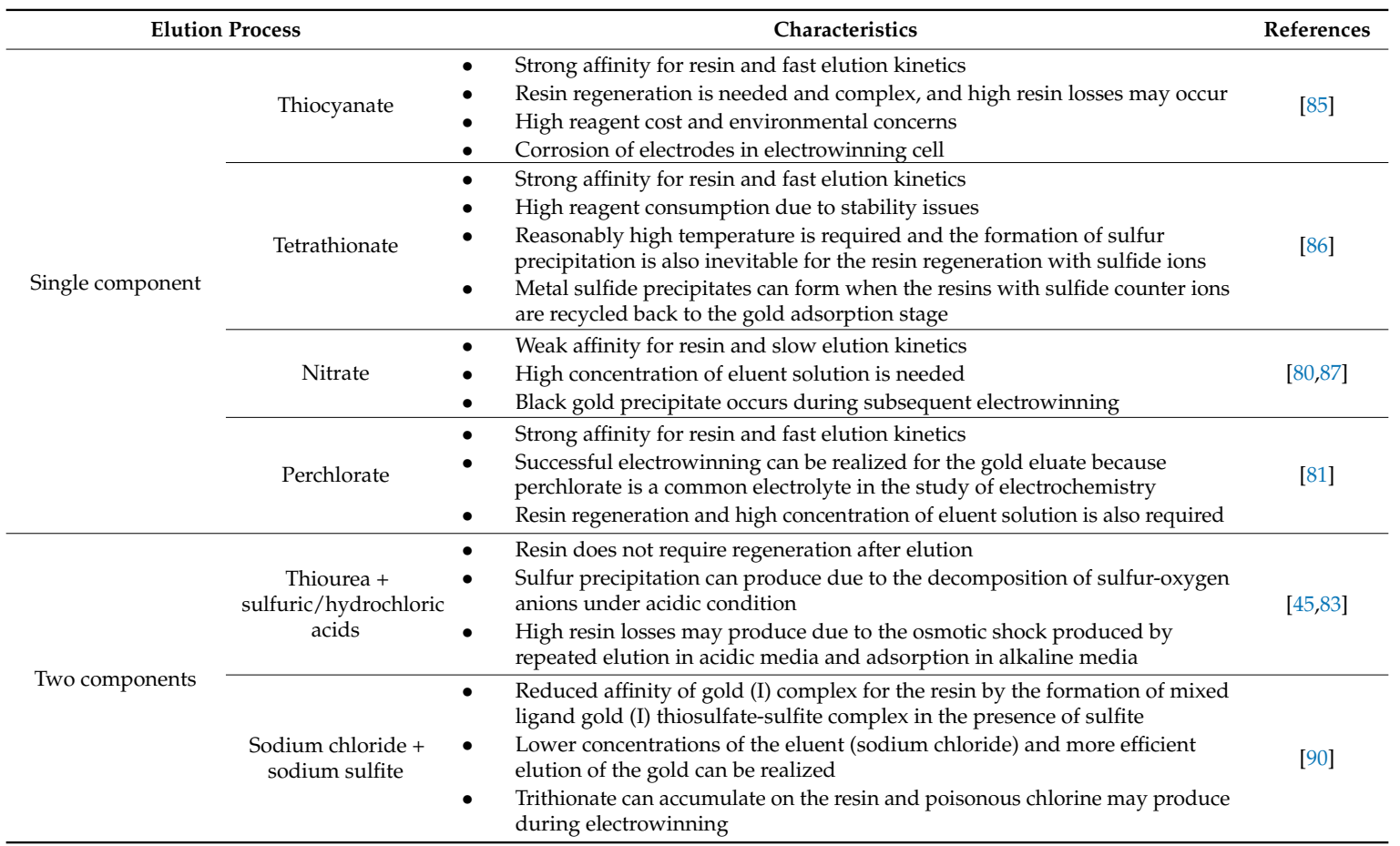

\section{Future Development}

Current research about gold recovery by ion exchange resins from pregnant thiosulfate solutions is in its infancy and a large number of further work is needed to make the recovery technique more efficient, economical and environmentally friendly. In terms of the main problems existing in the resin adsorption technique, the following countermeasures can be taken to optimize the technique.

(1) A suitable pretreatment can be conducted to remove the base metals before leaching to reduce their detrimental effects on subsequent gold recovery. To weaken or eliminate the competitive adsorption effects of copper (I) thiosulfate complexes and polythionates, one feasible measure is to minimize their generation during leaching through the elaborate control of reaction conditions. Another more effective measure is the replacement of traditional cupric-ammonia catalysis with other metals such as nickel- and cobalt-based catalysts. It reduces the consumption of thiosulfate and thus decreases the formation of polythionates. Also, the competitive adsorption of nickel and cobalt with gold will not occur because they do not complex with thiosulfate to form stable $\mathrm{Ni} / \mathrm{Co}-\mathrm{S}_{2} \mathrm{O}_{3}{ }^{2-}$ complexes, and therefore, the complicated and costly two-stage elution process can be substituted by a simple and low-cost one-stage process.

(2) The structure-activity relationship of the resin functional groups can be investigated through the first principle and quantum chemistry calculation to obtain the ideal resins that have strong affinity and high selectivity for gold (I) thiosulfate complex over copper (I) thiosulfate complex, polythionates and other metal thiosulfate complexes. As for the eluent, the mixed eluent of chloride and sulfite deriving from the concept of synergistic ion exchange needs to be further developed through the displacement of chloride by other environment-friendly weak eluents which have no negative effect on the subsequent electrowinning of gold eluate solutions.

Acknowledgments: Financial supports from the National Natural Science Foundation of China (grant No. 51504293 and 51574284), the China Postdoctoral Science Foundation (grant No. 2014M550422), Hunan Provincial Natural Science Foundation of China (grant No. 2015JJ3149), the Fundamental Research Funds for the Central Universities of Central South University (grant No. 2016zzts473), , and the Open-End Fund for the Valuable and Precision Instruments of Central South University (CSUZC201704) are all gratefully acknowledged. 
Author Contributions: Zhonglin Dong completed the main part of this review; Tao Jiang and Yongbin Yang completed the other parts of this review; Bin Xu and Qian Li offered advice for writing and revision of this review.

Conflicts of Interest: The authors declare no conflict of interest.

\section{References}

1. Jiang, T. Chemistry of Extractive Metallurgy of Gold; Hunan Science and Technology Press: Changsha, China, 1998.

2. Hilson, G.; Monhemius, A.J. Alternatives to cyanide in the gold mining industry: What prospects for the future? J. Clean. Prod. 2006, 14, 1158-1167. [CrossRef]

3. Xu, B.; Yang, Y.B.; Li, Q.; Jiang, T.; Liu, S.Q.; Li, G.H. The development of an environmentally friendly leaching process of a high C, As and Sb bearing sulfide gold concentrate. Miner. Eng. 2016, 89, $138-147$. [CrossRef]

4. Braul, P. Thiosulfate going commercial. Cim. Mag. 2013, 8, 42-45.

5. Choi, Y.; Baron, J.Y.; Wang, Q.; Langhans, J.; Kondos, P. Thiosulfate processing-From lab curiosity to commercial application. In Proceedings of the World Gold 2013, Brisbane, QLD, Australia, 26-29 September 2013.

6. Xu, B.; Kong, W.H.; Li, Q.; Yang, Y.B.; Jiang, T. A review of thiosulfate leaching of gold: Focus on thiosulfate consumption and gold recovery from pregnant solution. Metals 2017, 7, 222. [CrossRef]

7. Baron, J.Y.; Mirza, J.; Nicol, E.A.; Smith, S.R.; Leitch, J.J.; Choi, Y.; Lipkowski, J. SERS and electrochemical studies of the gold-electrolyte interface under thiosulfate based leaching conditions. Electrochim. Acta 2013, 111, 390-399. [CrossRef]

8. Zhang, X.M.; Senanayake, G. A review of ammoniacal thiosulfate leaching of gold: An update useful for further research in non-cyanide gold lixiviants. Miner. Process Extr. Metall. Rev. 2016, 37, 385-411. [CrossRef]

9. Lampinen, M.; Laari, A.; Turunen, I. Ammoniacal thiosulfate leaching of pressure oxidized sulfide gold concentrate with low reagent consumption. Hydrometallurgy 2015, 151, 1-9. [CrossRef]

10. Senanayake, G. Gold leaching by copper (II) in ammoniacal thiosulphate solutions in the presence of additives. Part I: A review of the effect of hard-soft and Lewis acid-base properties and interactions of ions. Hydrometallurgy 2012, 115-116, 1-20. [CrossRef]

11. Liu, X.L.; Xu, B.; Min, X.; Li, Q.; Yang, Y.B.; Jiang, T.; He, Y.H.; Zhang, X. Effect of pyrite on thiosulfate leaching of gold and the role of ammonium alcohol polyvinyl phosphate (AAPP). Metals 2017, 7, 278. [CrossRef]

12. Xu, B.; Yang, Y.B.; Li, Q.; Jiang, T.; Li, G.H. Stage leaching of a complex polymetallic sulfide concentrate: Focus on the extraction of Ag and Au. Hydrometallurgy 2016, 159, 87-94. [CrossRef]

13. Xu, B.; Yang, Y.B.; Jiang, T.; Li, Q.; Zhang, X.; Wang, D. Improved thiosulfate leaching of a refractory gold concentrate calcine with additives. Hydrometallurgy 2015, 152, 214-222. [CrossRef]

14. Xu, B.; Yang, Y.B.; Li, Q.; Yin, W.; Jiang, T.; Li, G.H. Thiosulfate leaching of Au, Ag and Pd from a high Au, Ag and Pd bearing decopperized anode slime. Hydrometallurgy 2016, 164, 278-287. [CrossRef]

15. Yang, Y.B.; Zhang, X.; Xu, B.; Li, Q.; Jiang, T.; Wang, Y.X. Effect of arsenopyrite on thiosulfate leaching of gold. Trans. Nonferrous Met. Soc. China 2015, 25, 3454-3460. [CrossRef]

16. Feng, D.; Van Deventer, J.S.J. Thiosulphate leaching of gold in the presence of orthophosphate and polyphosphate. Hydrometallurgy 2011, 106, 38-45. [CrossRef]

17. Feng, D.; Van Deventer, J.S.J. Effect of thiosulphate salts on ammoniacal thiosulphate leaching of gold. Hydrometallurgy 2010, 105, 120-126. [CrossRef]

18. Feng, D.; Van Deventer, J.S.J. Thiosulphate leaching of gold in the presence of ethylenediaminetetraacetic acid (EDTA). Miner. Eng. 2010, 23, 143-150. [CrossRef]

19. Feng, D.; Van Deventer, J.S.J. The role of amino acids in the thiosulphate leaching of gold. Miner. Eng. 2014, 24, 1022-1024. [CrossRef]

20. Liu, X.L.; Xu, B.; Yang, Y.B.; Li, Q.; Jiang, T.; Zhang, X.; Zhang, Y. Effect of galena on thiosulfate leaching of gold. Hydrometallurgy 2017, 17, 157-164. [CrossRef]

21. Xu, B.; Yang, Y.B.; Li, Q.; Jiang, T.; Zhang, X.; Li, G.H. Effect of common associated sulfide minerals on thiosulfate leaching of gold and the role of humic acid additive. Hydrometallurgy 2017, 17, 44-52. [CrossRef]

22. Jiang, T.; Xu, S.; Chen, J. Gold and silver extraction by ammoniacal thiosulfate catalytical leaching at ambient temperature. In Proceedings of the First International Conference of Modern Process Mineralogy and Mineral Processing, Beijing, China, 22-25 September 1992. 
23. Jiang, T.; Chen, J.; Xu, S. Electrochemistry and mechanism of leaching gold with ammoniacal thiosulfate. In Proceedings of the XVIII International Mineral Processing Congress, Sydney, Australia, 23-28 May 1993.

24. Breuer, P.L.; Jeffrey, M.I. An electrochemical study of gold leaching in thiosulfate solutions containing copper and ammonia. Hydrometallurgy 2002, 65, 145-157. [CrossRef]

25. Arima, H.; Fujita, T.; Yen, W.T. Using nickel as a catalyst in ammonium thiosulfate leaching for gold extraction. Mater. Trans. 2004, 45, 516-526. [CrossRef]

26. Aylmore, M.G. Treatment of a refractory gold-copper sulfide concentrate by copper ammoniacal thiosulfate leaching. Miner. Eng. 2001, 14, 615-637. [CrossRef]

27. Aylmore, M.G.; Muir, D.M.; Staunton, W.P. Effect of minerals on the stability of gold in copper ammoniacal thiosulfate solutions-The role of copper, silver and polythionates. Hydrometallurgy 2014, 143, 12-22. [CrossRef]

28. Wang, R.Y.; Brierley, J.A. Thiosulfate leaching follwing biooxidation pre-treatment for gold recovery from refractory carbonaceous-sulfidic ore. Miner. Eng. 1997, 49, 76-80.

29. Chandra, I.; Jeffrey, M.I. A fundamental study of ferric oxalate for dissolving gold in thiosulfate solutions. Hydrometallurgy 2005, 77, 191-201. [CrossRef]

30. Ficeriova, J.; Balaz, P.; Boldizarova, E.; Jelen, S. Thiosulfate leaching of gold from a mechanically activated CuPbZn concentrate. Hydrometallurgy 2002, 67, 37-43. [CrossRef]

31. Senanayake, G.; Zhang, X.M. Gold leaching by copper(II) in ammoniacal thiosulfate solutions in the presence of additives. Part II: Effect of residual $\mathrm{Cu}(\mathrm{II}), \mathrm{pH}$ and redox potentials on reactivity of colloidal gold. Hydrometallurgy 2012, 115-116, 21-29. [CrossRef]

32. Yu, H.; Zi, F.T.; Hu, X.Z.; Zhong, J.; Nie, Y.H.; Xiang, P.Z. The copper-ethanediamine-thiosulphate leaching of gold ore containing limonite with cetyltrimethyl ammonium bromide as the synergist. Hydrometallurgy 2014, 150, 178-183. [CrossRef]

33. Arima, H.; Fujita, T.; Yen, W.T. Gold Cementation from ammonium thiosulfate solution by zinc, copper and aluminium powders. Mater. Trans. 2002, 43, 485-493. [CrossRef]

34. Hu, J.X.; Gong, Q. Recovery of gold from thiosulfate solution. Eng. Chem. Metall. 1989, 10, 45-50. (In Chinese)

35. Guerra, E.; Dreisinger, D.B. A study of the factors affecting copper cementation of gold from ammoniacal thiosulphate solution. Hydrometallurgy 1999, 51, 155-172. [CrossRef]

36. Choo, W.L.; Jeffrey, M.I. An electrochemical study of copper cementation of gold(I) thiosulfate. Hydrometallurgy 2004, 71, 351-362. [CrossRef]

37. Hiskey, J.B.; Lee, J. Kinetics of gold cementation on copper in ammoniacal thiosulfate solution. Hydrometallurgy 2003, 69, 45-56. [CrossRef]

38. Lee, J. Gold Cementation on Copper in Thiosulfate Solution: Kinetic, Electrochemical, and Morphological Studies. Ph.D. Thesis, Department of Materials Science and Engineering, University of Arizona, Tucson, AZ, USA, December 2003.

39. Awadalla, F.T.; Ritcey, G.M. Recovery of gold from thiourea, thiocyanate or thiosulfate solutions by reduction-precipitation with a stabilized form of sodium borohydride. Sep. Sci. Technol. 1990, 26, 1207-1228. [CrossRef]

40. Groves, W.D.; Blackman, L. Recovery of Precious Metals from Evaporite Sediments. U.S. Patent 5,405,430, 11 April 1995.

41. Kerley, B.J. Recovery of Precious Metals from Difficult Ores. U.S. Patent 4,269,622, 26 May 1981.

42. Navarro, P.; Vargas, C.; Alonso, M.; Alguacil, F.J. The adsorption of gold on activated carbon from thiosulfate-ammoniacal solutions. Gold Bull. 2006, 39, 93-97. [CrossRef]

43. Navarro, P.; Vargas, C.; Alonso, M.; Alguacil, F.J. Towards a more environmentally friendly process for gold: Models on gold adsorption onto activated carbon from ammoniacal thiosulfate solutions. Desalination 2007, 211, 58-63. [CrossRef]

44. Marchbank, A.R.; Thomas, K.G.; Dreisinger, D.; Fleming, C. Gold Recovery from Refractory Carbonaceous Ores by Pressure Oxidation and Thiosulfate Leaching. U.S. Patent 5,536,297, 28 July 1996.

45. Kononova, O.N.; Kholmogorov, A.G.; Kononov, Y.S.; Pashkov, G.L.; Kachin, S.V.; Zotova, S.V. Sorption recovery of gold from thiosulphate solutions after leaching of products of chemical preparation of hard concentrates. Hydrometallurgy 2001, 59, 115-123. [CrossRef]

46. Vargas, C.; Navarro, P.; Araya, E.; Pavez, F.; Alguacil, F.J. Recovery of gold from solutions with ammonia and thiosulfate using activated carbon. Rev. Metal. 2006, 42, 222-233. [CrossRef] 
47. Mohansingh, R. Adsorption of Gold from Gold Copper Ammonium Thiosulfate Complex onto Activated Carbon and Ion Exchange Resins. Master's Thesis, University of Nevada, Reno, NV, USA, May 2000.

48. Aylmore, M.G.; Muir, D.M. Thiosulfate leaching of gold-A review. Miner. Eng. 2001, 14, 135-174. [CrossRef]

49. Gallagher, N.P.; Hendrix, J.L.; Milosavljevic, E.B.; Nelson, J.H.; Solujic, L. Affinity of activated carbon towards some gold(I) complexes. Hydrometallurgy 1990, 25, 305-316. [CrossRef]

50. Gallagher, N.P. The affinity of carbon for gold complexes: dissolution of finely disseminated gold using a flow electrochemical cell. J. Electrochem. Soc. 1990, 21, 2546-2551. [CrossRef]

51. Lulham, J.P.; Lindsay, D. Gold Recovery from Thiosulfate Ore Leaching Solutions. International Patent WO/1991/011539, 8 August 1991.

52. Parker, G.K.; Gow, R.N.; Young, C.A.; Twidwell, L.G.; Hope, G.A. Spectroelectrochemical investigation of the reaction between adsorbed cuprous cyanide and gold thiosulfate ions at activated carbon surfaces. In Proceedings of the Hydrometallurgy 2008, Sixth International Symposium, Littleton, CO, USA, 17-20 August 2008.

53. Young, C.A.; Gow, R.N.; Twidwell, L.G.; Parker, G.K.; Hope, G.A. Cuprous cyanide adsorption on activated carbon: pretreatment for gold take-up from thiosulfate solutions. In Proceedings of the Hydrometallurgy 2008, Sixth International Symposium, Littleton, CO, USA, 17-20 August 2008.

54. Yu, H.; Zi, F.T.; Hu, X.Z.; Nie, Y.H.; Xiang, P.Z.; Xu, J.; Chi, H. Adsorption of the gold-thiosulfate complex ion onto cupric ferrocyanide( $\mathrm{CuFC})$-impregnated activated carbon in aqueous solutions. Hydrometallurgy 2015, 154, 111-117. [CrossRef]

55. Chen, J.Y.; Deng, T.; Zhu, G.C.; Zhao, J. Leaching and recovery of gold in thiosulfate based system-A research summary at ICM. Trans. Indian Inst. Met. 1996, 49, 841-849.

56. Zhao, J.; Wu, Z.C.; Chen, J.Y. Extraction of gold from thiosulfate solutions with alkyl phosphorus esters. Hydrometallurgy 1997, 46, 363-372. [CrossRef]

57. Zhao, J.; Wu, Z.C.; Chen, J.Y. Extraction of gold from thiosulfate solutions using amine mixed with neutral donor reagents. Hydrometallurgy 1998, 48, 133-144. [CrossRef]

58. Zhao, J.; Wu, Z.C.; Chen, J.Y. Gold extraction from thiosulfate solutions using mixed amines. Solvent Extr. Ion Exch. 1998, 16, 1407-1420. [CrossRef]

59. Zhao, J.; Wu, Z.C.; Chen, J.Y. Solvent extraction of gold in thiosulfate solutions with amines. Solvent Extr. Ion Exch. 1998, 16, 527-543. [CrossRef]

60. Zhao, J.; Wu, Z.C.; Chen, J.Y. Separation of gold from other metals in thiosulfate solutions by solvent extraction. Sep. Sci. Technol. 1999, 34, 2061-2068. [CrossRef]

61. Virnig, M.J.; Sierakoski, J.M. Ammonium Thiosulfate Complex of Gold or Silver and an Amine. U.S. Patent 6,197,214, 6 March 2001.

62. Liu, K.J.; Yen, W.T.; Shibayama, A.; Miyazaki, T.; Fujita, T. Gold extraction from thiosulfate solution using trioctylmethylammonium chloride. Hydrometallurgy 2004, 71, 41-53.

63. Grosse, A.C.; Dicinoski, G.W.; Shaw, M.J.; Haddad, P.R. Leaching and recovery of gold using ammoniacal thiosulfate leach liquors (a review). Hydrometallurgy 2003, 69, 1-21. [CrossRef]

64. Sullivan, A.M.; Kohl, P.A. Electrochemical study of the gold thiosulfate reduction. J. Electrochem. Soc. 1997, 144, 1686-1690. [CrossRef]

65. Sullivan, A.M.; Kohl, P.A. The autocatalytic deposition of gold in nonalkaline, gold thiosulfate electroless bath. J. Electrochem. Soc. 1995, 142, 2250-2255. [CrossRef]

66. Abbruzzese, C.; Fornari, P.; Massidda, R.; Veglio, F.; Ubaldini, S. Thiosulfate leaching for gold hydrometallurgy. Hydrometallurgy 1995, 39, 265-276. [CrossRef]

67. Osaka, T.; Kodera, A.; Misato, T.; Homma, T.; Okinaka, Y. Electrodeposition of soft gold from a thiosulfate-sulfite bath for electronics applications. J. Electrochem. Soc. 1997, 144, 3462-3469. [CrossRef]

68. Aledresse, A. Gold Recovery from Low Concentrations using Nanoporous Silica Adsorbent. Ph.D. Thesis, Laurentian University, Sudbury, ON, Canada, January 2009.

69. Boissiere, C.; Larbot, A.; Van der lee, A.; Kooyman, P.J.; Prouzet, E. A new synthesis of mesoporous MSU-X silica controlled by a two-step pathway. Chem. Mater. 2000, 12, 2902-2913. [CrossRef]

70. Fotoohi, B.; Mercier, L. Modification of pore structure and functionalization in MSU-X silica and application in adsorption of gold thiosulfate. Microporous Mesoporous Mater. 2014, 190, 255-266. [CrossRef]

71. Fotoohi, B.; Mercier, L. Recovery of precious metals from ammoniacal thiosulfate solutions by hybrid mesoporous silica: 2-A prospect of PGM adsorption. Sep. Purif. Technol. 2015, 149, 82-91. [CrossRef] 
72. Fotoohi, B.; Mercier, L. Recovery of precious metals from ammoniacal thiosulfate solutions by hybrid mesoporous silica: 3-Effect of contaminants. Sep. Purif. Technol. 2015, 139, 4-24. [CrossRef]

73. Fotoohi, B.; Mercier, L. Recovery of precious metals from ammoniacal thiosulfate solutions by hybrid mesoporous silica: 1-Factors affecting gold adsorption. Sep. Purif. Technol. 2014, 127, 84-96. [CrossRef]

74. Grosse, A.C. The Development of Resin Sorbents Selective for Gold in Ammoniacal Thiosulfate Leach Liquors. Ph.D. Thesis, School of Chemistry, University of Tasmania, Australia, September 2006.

75. Atluri, V.P. Recovery of Gold and Silver from Ammoniacal Thiosulfate Solutions Containing Copper by Ion Exchange Resin Method. Master's Thesis, Department of Materials Science and Engineering, University of Arizona, Tucson, AZ, USA, December 1987.

76. Fleming, C.A.; Cromberge, G. The extraction of gold from cyanide solutions by strong-and weak-base anion-exchange resins. J. South. Afr. Inst. Min. Metall. 1984, 8, 125-137.

77. Zhang, H.G.; Dreisinger, D.B. The adsorption of gold and copper onto ion-exchange resins from ammoniacal thiosulfate solutions. Hydrometallurgy 2002, 66, 67-76. [CrossRef]

78. Kononova, O.N.; Shatnykh, K.A.; Prikhod'ko, K.V.; Kashirin, D.M. Ion exchange recovery of gold(I) and Silver (I) from thiosulfate solutions. Russ. J. Phys. Chem. A 2009, 83, 2340-2345. [CrossRef]

79. Zhang, H.G.; Dreisinger, D.B. The recovery of gold from ammonical thiosulfate solutions containing copper using ion exchange resin columns. Hydrometallurgy 2004, 72, 225-234. [CrossRef]

80. O'Malley, G.P. Recovery of Gold from Thiosulfate Solutions and Pulps with Anion Exchange Resins. Ph.D. Thesis, Murdoch University, Perth, Australia, March 2002.

81. Arima, H.; Fujita, T.; Yen, W.T. Gold recovery from nickel catalyzed ammonium thiosulfate solution by strongly basic anion exchange resin. Mater. Trans. 2003, 44, 2099-2107. [CrossRef]

82. Min, X. Research on the Electrochemistry of Thiosulfate Gold Leaching Catalyzed by Co/Ni-NH3. Master's Thesis, Central South University, Changsha, China, June 2017. (In Chinese)

83. Lai, C.S. The Analysis and Recovery of Gold from Ammonium Thiosulfate Leach Solutions. Master's Thesis, Kunming University of Science and Technology, Kunming, China, June 2011. (In Chinese)

84. Fleming, C.A.; Cromberge, G. The elution of aurocyanide from strong- and weak-base resins. J. South. Afr. Inst. Min. Metall. 1984, 84, 269-280.

85. Thomas, K.G.; Fleming, C.A.; Marchbank, A.R.; Dreisinger, D.B. Gold Recovery from Refractory Carbonaceous Ores by Pressure Oxidation, Thiosulfate Leaching and Resin-in-Pulp Adsorption. U.S. Patent 5,785,736, 28 July 1998.

86. Fleming, C.A.; Mcmullen, J.; Thomas, K.G.; Wells, J.A. Recent advances in the development of an alternative to the cyanidation process: Thiosulfate leaching and resin in pulp. Miner. Metall. Process. 2003, 20, 1-9.

87. Nicol, M.G.; O'Malley, G.P. Recovering gold from thiosulfate leach pulps via ion exchange. JOM 2002, 54, 44-46. [CrossRef]

88. Nicol, M.J.; O'Malley, G.P. Cyanide: Social, Industrial and Economic Aspects; The Minerals, Metals and Materials Society: Warrendale, PA, USA, 2001.

89. Perera, W.N.; Senanayake, G.; Nicol, M.J. Interaction of gold(I) with thiosulfate-sulfite mixed ligand systems. Inorg. Chim. Acta 2005, 358, 2183-2190. [CrossRef]

90. Jeffrey, M.I.; Hewitt, D.M.; Dai, X.; Brunt, S.D. Ion exchange adsorption and elution for recovering gold thiosulfate from leach solutions. Hydrometallurgy 2010, 100, 136-143. [CrossRef]

91. Naito, K.; Shieh, M.C.; Okabe, T. Chemical behaviour of low valence sulfur compounds. V. Decomposition and oxidation of tetrathionate in aqueous ammonia solution. Bull. Chem. Soc. Jpn. 1970, 43, 1372-1376. [CrossRef]

92. Rolia, E.; Chakrabarti, C.L. Kinetics of decomposition of tetrathionate, trithionate and thiosulphate in alkaline media. Environ. Sci. Technol. 1982, 16, 852-857. [CrossRef] [PubMed]

93. Zhang, H.G.; Dreisinger, D.B. The kinetics for the decomposition of tetrathionate in alkaline solutions. Hydrometallurgy 2002, 66, 59-65. [CrossRef]

94. Breuer, P.L.; Jeffrey, M.I. The effect of ionic strength and buffer choice on the decomposition of tetrathionate in alkaline solutions. Hydrometallurgy 2004, 72, 335-338. [CrossRef]

95. Varga, D.; Horvath, A.K. Kinetics and mechanism of the decomposition of tetrathionate ion in alkaline medium. Inorg. Chem. 2007, 46, 7654-7661. [CrossRef] [PubMed]

96. Ferron, C.J.; Turner, D.W.; Stogran, K. Thiosulfate leaching of gold and silver ores: An old process revisited. In Proceedings of the CIM 100th Annual General Meeting, Montreal, QC, Canada, 3-7 May 1998. 
97. Navarro, P.; Vargas, C.; Reveco, V.; Orellana, J. Recovery of gold from ammonia-thiosulfate media with amberlite IRA-410 ionic exchange resin. Rev. Metal. 2006, 42, 354-366. [CrossRef]

98. Zhang, H.G.; Dreisinger, D.B. Gold Recovery from Thiosulfate Leaching. U.S. Patent 6,632,264, 14 October 2003.

99. Chaparro, M.; Munive, G.; Guerrero, P.; Parga, J.R.; Vazquez, V.; Valenzuela, J.L. Gold adsorption in thiosulfate solution using anionic exchange resin. J. Multidiscip. Eng. Sci. Technol. 2015, 2, 2159-2163.

100. Clifford, D.; Weber, W.J. The determinants of divalent/monovalent selectivity in anion exchangers. React. Polym. 1983, 1, 77-89. [CrossRef]

101. Riveros, P.A. Selectivity aspects of the extraction of gold from cyanide solutions with ion-exchange resins. Hydrometallurgy 1993, 33, 43-58. [CrossRef]

102. Averston, J.; Everest, D.A.; Wells, R.A. Adsorption of gold from cyanide solutions by anionic resins. J. Chem. Soc. 1958, 231-239. [CrossRef]

103. Hardland, C.E. Ion Exchange: Theory and Practice; The Royal Society of Chemistry: Cambridge, UK, 1994.

104. Lukey, G.C.; Van Deventer, J.S.J.; Shallcross, D.C. Selective elution of copper and iron cyanide complexes from an ion exchange resins using saline solutions. Hydrometallurgy 1999, 56, 217-236. [CrossRef]

105. Iguchi, A. The separation of sulfate, sulfite, thiosulfate and sulfite ions with anion-exchange resins. B. Chem. Soc. Jpn. 1958, 31, 600-605. [CrossRef]

106. Eusebius, L.C.T.; Ghose, A.K.; Mahan, A.; Dey, A.K. Thiosulfate as a complexing agent in the separation of cations by anion-exchange chromatography. Analyst 1980, 105, 52-59. [CrossRef]

107. Weir, S.I.; Butler, E.C.V.; Haddad, P.R. Ion chromatography with UV detection for the determination of thiosulfate and polythionates in saline waters. J. Chromatogr. A 1994, 671, 197-203. [CrossRef]

(C) 2017 by the authors. Licensee MDPI, Basel, Switzerland. This article is an open access article distributed under the terms and conditions of the Creative Commons Attribution (CC BY) license (http:// creativecommons.org/licenses/by/4.0/). 